\title{
Análise do processo de acolhimento em um Centro de Atenção Psicossocial Infantojuvenil:
} considerações de uma investigação etnográfica

\author{
Carolina Pinheiro Moreira ${ }^{(a)}$ \\ Mônica de Oliveira Nunes de Torrenté(b) \\ Vládia Jamile dos Santos Jucá(c)
}

Moreira CP, Torrenté MON, Jucá VJS. Analysis of the embracement process in a Child and Adolescent Psychosocial Healthcare Center: considerations from an ethnographic investigation. Interface (Botucatu). 2018; 22(67):1123-34.

The present article analyzes how children and adolescents are receveid by professionals at a Child and Adolescent Psychosocial Healthcare Center (CAPsi) in the municipality of Salvador, Bahia, Brazil. In an ethnographic study, institutional and clinical aspects were analyzed, starting with the arrival of first time users to the center and including referrals given to their cases. The following categories emerged from data analysis: the organization of the work environment, interdisciplinary work processes, psychosocial assessment strategies, and continuity of care. The manner in which the first meeting between users and professionals is organized and experienced is an important indication of how the patient-professional relationship will develop and of the responsibility taken by professionals for the cases that arrive at the center. Furthermore, the data show the specific need to invest in the education of mental health workers and the reorganization of work processes in the CAPSi.

Key words: Child and adolescent mental health. Embracement. Work processes.
Este artigo analisa as práticas de acolhimento a crianças e adolescentes desenvolvidas pelos profissionais de um Centro de Atenção Psicossocial Infantojuvenil (CAPSi) do município de Salvador, Bahia, Brasil. Em uma investigação etnográfica, foram analisados os aspectos institucionais e clínicos envolvidos desde a chegada do usuário pela primeira vez ao serviço até o encaminhamento dado ao seu caso. $\mathrm{Na}$ análise, foram utilizadas categorias que se referem à organização da ambiência, aos processos de trabalho interdisciplinares, às estratégias de avaliação psicossocial e à continuidade do cuidado. Evidencia-se como a organização e vivência do encontro de usuários e profissionais no momento do acolhimento são importantes demarcadores para a forma de vinculação e responsabilização com os casos que chegam ao serviço, apontando também necessidades específicas para investimento na formação dos trabalhadores de saúde mental e na reorganização dos processos de trabalho no CAPSi.

Palavras-chave: Saúde mental infantojuvenil. Acolhimento. Processos de trabalho. 


\section{Introdução}

Os Centros de Atenção Psicossocial Infantojuvenil (CAPSi) foram dispositivos propostos a partir de 2002, que, como as demais modalidades de CAPS, configuram-se como serviços de base territorial, de natureza pública, com a função de oferecer atenção em saúde mental com vistas à integralidade do cuidado ${ }^{1}$. Os CAPSi têm a finalidade de atender casos de maior gravidade e ordenar a demanda em saúde mental infantojuvenil no seu território de abrangência. São prioritários os atendimentos de crianças e adolescentes com graves comprometimentos psíquicos (como autistas, psicóticos, neuróticos graves), incluindo aqueles decorrentes de uso de substâncias psicoativas e aqueles cuja problemática incida diretamente em prejuízos psicossociais severos, afetando a capacidade do sujeito de estabelecer ou manter os laços sociais em seu entorno e realizar projetos de vida ${ }^{2-4}$. Destaca-se aqui a necessidade de problematização sobre a denominação de "gravidade" dos quadros de sofrimento na infância e adolescência, distintos daqueles aportados para o público adulto, uma vez que os agravos vivenciados nesta fase da vida têm impactos mais profundos para o desenvolvimento futuro dos sujeitos.

Compreendemos, nesta pesquisa, que o acolhimento, além de ser uma ferramenta que altera a ordenação dos processos de trabalho em saúde mental, configura-se como espaço privilegiado de expressão da heterogeneidade de concepções e valores em torno da atenção à saúde mental, permitindo acessar como as construções morais operam nas percepções em torno do sofrimento dos usuários e das práticas de cuidado escolhidas.

O acolhimento representa uma das principais diretrizes da Política Nacional de Humanização do SUS e pode ser compreendido como o primeiro contato com quem procura o serviço, que tem nesse momento seus recursos postos à prova: quem atende, o que pode oferecer, como pode acolher, avaliar e discriminar a demanda 5 . O acolhimento deve ser também interpretado como um dispositivo relacional que, articulado ao estabelecimento de vínculo entre trabalhadores, usuários e gestores, edifica as possibilidades de efetivação da humanização do cuidado, transversalizando toda ação terapêutica do serviço ${ }^{6}$.

É possível identificarmos distintas dimensões do processo de acolhimento: uma dimensão ética, referente ao compromisso de reconhecimento do outro em sua singularidade, em seu sofrimento, em suas potencialidades e em seu modo de vida específico; uma dimensão relacional, no desenvolvimento de habilidades que permitam receber, escutar e tratar as demandas com o estabelecimento de uma relação de confiança e apoio entre trabalhadores e usuários; uma dimensão técnica, que exige a articulação dos saberes da equipe multiprofissional, a fim de construir e articular respostas às necessidades identificadas nos casos acolhidos; e uma dimensão política, pois implica em um compromisso coletivo de potencializar nas relações a autonomia e protagonismo do sujeito; e, assim, assume a dimensão de reorientação do serviço. Nessa direção, o acolhimento ocupa um lugar central no projeto terapêutico institucional e, por isso, deve ser priorizado na organização dos processos de trabalho e cuidado e ser considerado nos processos de educação permanente das equipes, para que não se torne uma triagem burocrática ${ }^{7,8}$.

Nos serviços da Rede de Atenção Psicossocial (Raps), sobretudo nos CAPS, o acolhimento apresenta-se como possibilidade de receber o sujeito em sofrimento mental em sua integralidade, indo além de uma avaliação psicopatológica e avançando na tentativa de compreensão do contexto vivencial, relacional e comunitário em que esse sofrimento se configura em sua especificidade. Dessa forma, podemos distinguir o acolhimento nos serviços de saúde mental em duas perspectivas interconectadas.

Uma primeira perspectiva é institucional, pressupondo uma estética, um ambiente e formas de relação que facilitem o sentimento de pertença, segurança e acolhimento, que veicule a disponibilidade para o cuidado incondicional e que crie condições adequadas para a expressão genuína do sujeito. $O$ acolhimento envolve também uma perspectiva clínica que exige habilidades técnicas e apropriação sobre o funcionamento do serviço e da rede de atenção e é capaz de viabilizar uma avaliação psicossocial que faça o delineamento inicial sobre a expressão e história de sofrimento e vulnerabilidade, indo além da identificação de sintomas, buscando a dimensão subjetiva destes, mas também vislumbrando ações e articulações concernentes às demandas apresentadas pelo sujeito e seus cuidadores. 
Por reconhecer a importância do acolhimento nos serviços substitutivos, com destaque para o CAPSi, principalmente quanto à vinculação e à responsabilização sobre os casos, este artigo teve por objetivo descrever e analisar a organização institucional e os processos de trabalho envolvidos no acolhimento a crianças e adolescentes em sofrimento psíquico, desde a sua chegada na unidade até o encaminhamento dado ao caso.

\section{Metodologia}

A partir do método etnográfico, foi realizada a imersão por três meses no cotidiano da instituição, observando, analisando e registrando em diário de campo as dinâmicas que se operam entre técnicos e entre estes com usuários e familiares, com enfoque no processo de acolhimento.

A escolha pela etnografia deu-se por esta permitir o conhecimento das dinâmicas socioculturais e dos modos de subjetividade individual e coletiva forjados nas instituições e grupos sociais, com a apreensão da singularidade dos modos de produzir, conceber, significar e vivenciar das pessoas e grupos culturais. Nesse sentido, compreendem-se os fenômenos em análise como configurações sociais cuja construção está em íntima dependência da forma como o sujeito a vivencia e dos recursos que Ihes são socialmente disponibilizados para lidar com as situações concretas ${ }^{9}$.

Utilizaremos neste estudo a concepção proposta por Nunes et al..$^{10}$ de que os CAPS devem ser compreendidos enquanto universos culturais próprios, com seus idiomas, práticas e significantes terapêuticos. Nesse contexto, as experiências individuais e coletivas são articuladas a partir do idioma cultural, expresso em recursos, mecanismos e significantes, capazes de produzir sentido e ação concreta. Os CAPS se constituem, nesta perspectiva, a partir da combinação entre uma orientação pautada em um modelo ideal, baseado nos pressupostos da atenção psicossocial e da Reforma Psiquiátrica Brasileira, e das peculiaridades produzidas pelo seu contexto local e pelos atores que o constituem.

Esta pesquisa foi desenvolvida em um CAPSi da cidade de Salvador. Como o município só conta com dois serviços especializados para atenção psicossocial de crianças e adolescentes, a divisão territorial entre eles é complexa, e, na realidade cotidiana, ambos atendem a todo o território municipal.

No início de 2016, a equipe técnica era composta por 22 profissionais estatutários: três psicólogas, dois professores de educação física, três assistentes sociais, uma enfermeira, cinco técnicas de enfermagem, três terapeutas ocupacionais, uma farmacêutica, duas psiquiatras e dois oficineiros (profissionais de nível médio). Desse quadro de profissionais, três eram do sexo masculino e 19 do sexo feminino. O serviço era gerido por uma gerente administrativa (cargo de confiança política). Esse CAPSi contava ainda com grupos de estagiários dos cursos de Psicologia e Enfermagem e com residentes de um programa de residência multiprofissional em saúde mental - todos estes permaneciam em média seis meses no acompanhamento das atividades do serviço.

No período de realização da coleta dos dados, os profissionais que assumiram o acolhimento (enquanto primeiro contato com os casos que chegam ao serviço) foram: uma assistente social, uma farmacêutica, dois oficineiros, quatro técnicas de enfermagem e, pontualmente, uma psiquiatra. Essa escolha era definida de acordo com a disponibilidade pessoal dos profissionais e buscava-se uma rotatividade periódica (a cada seis meses) dos profissionais nessa função.

Para a análise dos dados, foram utilizadas categorias que se referem à organização da ambiência, aos processos de trabalho interdisciplinares, às estratégias de avaliação psicossocial e à continuidade do cuidado.

Esta pesquisa foi aprovada pelo Comitê de Ética em Pesquisa, sendo observadas as recomendações e normas da Comissão Nacional de Ética em Pesquisa (Conep) - Resolução CNS 466/12 - a respeito de pesquisas que envolvem seres humanos, e teve anuência da Secretaria Municipal de Saúde de Salvador para sua realização. Todos os participantes assinaram o Termo de Consentimento Livre e Esclarecido, disponibilizando a publicação das informações produzidas nesta investigação. 


\section{Resultados e discussão}

\section{Sobre o espaço acolhedor}

Sobre a chegada do usuário no serviço, destacou-se um aspecto reconhecido pela equipe como uma mudança recente de impacto positivo: a estética e ambiência do serviço. Esta unidade herdou o espaço físico de um ambulatório de saúde mental que funcionava nas instalações de um hospital psiquiátrico. Isso significa que, ao contrário do que é proposto pela Raps sobre os espaços físicos dos CAPS ${ }^{11}$, este serviço traz, em suas paredes de azulejo branco, aliado à pouca iluminação e às janelas altas gradeadas, marcas de um espaço manicomial.

No âmbito da humanização da atenção em saúde, considera-se o local físico enquanto espaço social, profissional e de relações interpessoais, que deve proporcionar uma atenção acolhedora, resolutiva e humana na produção de ambientes que viabilizem, além de privacidade e conforto, a produção de subjetividades no encontro entre sujeitos para reflexão sobre os processos de trabalho e cuidado ${ }^{12}$.

As mudanças recentes, operadas pelos técnicos e residentes multiprofissionais em atuação no serviço, incluíram a criação de espaços de livre expressão nas paredes da sala de espera, com lápis coloridos, tintas e revistas à disposição; afixação de artes e poesias; e pequenas mesas com cadeiras em que as crianças podiam desenhar, escrever e se expressar antes dos atendimentos. Aliado a isso, a realização de uma oficina de grafite deu novas cores ao muro que une o CAPSi ao hospital psiquiátrico vizinho.

Outro aspecto discutido pela equipe foi o tempo e as filas de espera no acolhimento. No contexto desta unidade, a concentração do acolhimento em poucos turnos semanais implicava na limitação dos casos a serem atendidos. Tal circunstância acabou por gerar uma dinâmica na qual os usuários começavam a chegar até duas horas antes do horário de abertura do serviço para garantia de atendimento ou aguardavam do início do turno matutino até o início da tarde para serem atendidos. Por vezes, usuários com familiares residentes de bairros distantes tinham que retornar às suas residências sem terem sua demanda escutada.

A naturalização do discurso sobre as filas de espera do SUS entre alguns profissionais confrontavase com a problematização feita por outros sobre o diferencial que precisava ser analisado no contexto de um serviço de saúde mental. O sofrimento vivenciado pelos usuários e familiares que buscam tal serviço é atravessado por uma urgência de escuta e acolhimento - assim, ainda que a resposta a ser dada implique em uma espera posterior, em ter que retornar em outro dia ao local, é importante que a equipe compreenda o acolhimento para além da realização de um procedimento, mantendo uma postura acolhedora diante da demanda apresentada e a avaliação prévia sobre a possibilidade de espera ou não ${ }^{13}$ do caso.

\section{Sobre o profissional acolhedor}

Um aspecto técnico importante que merece destaque nesta discussão é a escolha dos profissionais que atuam como acolhedores. A realização do acolhimento é proposta como uma atividade do campo da saúde mental, que, ao assumir a complexidade do sofrimento psíquico, propõe sua compreensão a partir da transversalidade entre os saberes ${ }^{14}$, não devendo ser específica a nenhuma categoria profissional. Porém, ao atribuirmos ao acolhimento a importância de ser uma estratégia essencial para a avaliação inicial dos casos, para a construção de vínculo entre usuário e familiares com a instituição e para construção de respostas às demandas apresentadas pelos sujeitos, é preciso estabelecer a premissa de que não é qualquer profissional que pode assumir tal função. Apontamos aqui algumas habilidades relacionais, conhecimentos clínicos e a apropriação sobre aspectos do funcionamento do serviço e da rede de atenção integral que consideramos necessárias ao profissional atuante no acolhimento em um CAPSi.

Entre as habilidades relacionais, podemos elencar algumas que se apresentam como fundamentais no exercício de receber um sujeito em sofrimento em um serviço de saúde mental. Peixoto et 
al. ${ }^{15}$ apontam a empatia como elemento relacional que permite uma melhor compreensão da experiência do usuário e que favorece a relação entre este e o profissional, sendo fundamental para o desenvolvimento do processo de cuidado. A empatia é apresentada pelos autores como "sentir ou representar algo semelhante ao que é a experiência do outro" (p. 881).

Outro aspecto é a disponibilidade para uma escuta atenta e para a interação com um sujeito que pode expressar seu sofrimento de forma difícil de ser compreendida, mas necessariamente possível de ser acolhida. Pinto ${ }^{16}$ avalia que o sucesso da clínica nos CAPSi parece estar atrelado à sua capacidade de "suportar as idiossincrasias do ser humano, não acolhidas em outros serviços, fazendo falar o sofrimento, ao invés de oferecer-lhe uma escuta surda" (p. 11).

Atuar no acolhimento em um CAPSi envolve uma postura ética que pressupõe desconstruções de ordem moral, das significações elaboradas em torno do ideal de infância, adolescência, família e saúde. Exige do profissional um descentramento de sua habitual leitura de mundo para contextualização subjetiva e cultural da experiência do usuário ${ }^{15}$. Tensiona também o redimensionamento do lugar de saber-poder do profissional em relação ao usuário de um serviço público, com o respeito ao seu modo de vida e aos saberes produzidos sobre sua existência ${ }^{17}$. Essas desconstruções exigidas para o encontro genuíno com os sujeitos em sofrimento são essenciais para a emergência no usuário do sentimento de ser acolhido e, a partir daí, para a construção do vínculo. Sobre essa questão, ao discutir-se um caso de uma adolescente acolhida no serviço, uma profissional destaca:

Às vezes as adolescentes chegam aqui maquiadas, bem-arrumadas, têm até namorado. Percebo que é difícil para a equipe reconhecer que uma menina dessas pode ter um sofrimento grave. É preciso escutar o que elas têm a dizer sobre como estão, o que sentem. Elas muitas vezes estão se cortando, tentam suicídio. É mais fácil para a equipe dizer que um caso é para cá quando chega todo desorganizado. (Diário de campo, novembro de 2015)

Maynart et al. ${ }^{18}$ afirmam que a não realização de uma escuta qualificada no acolhimento a um sujeito em sofrimento é capaz de produzir insatisfação no usuário e gerar sentimentos negativos em relação ao profissional e à instituição, bem como o bloqueio à expressão de seu sofrimento, aumentando os riscos e vulnerabilidades do quadro, com consequente agravamento do sofrimento mental.

A disponibilidade à convivência e diálogo com a diferença dos modos de significar e agir dos sujeitos precisa ser vivenciada não só na relação com os usuários e familiares, mas também na equipe multiprofissional. É imprescindível assumirmos que, em equipes com essa diversidade de formações e experiências (profissionais e pessoais), confrontam-se diferentes valores morais, visões de mundo e referências culturais, o que acaba por gerar, por vezes, campos de disputa e tensão. Eventualmente, esse conflito ocorre no âmbito teórico-técnico, com confrontação de modelos de atenção e concepções sobre o cuidado, avançando inclusive no terreno ético, em momentos em que se confrontam a ética de manutenção da ordem da instituição e a ética do sujeito.

No serviço investigado, o acolhimento aos usuários que chegam pela primeira vez é realizado por dois profissionais de categorias diferentes. Esse formato foi proposto pela equipe por compreender que tal espaço demanda uma multiplicidade de saberes, necessários para ampliar a capacidade de análise e de oferta de respostas às especificidades dos casos acolhidos. No período da investigação, observou-se que, na conformação das duplas, não havia a exigência de garantia de um técnico de nível universitário, com existência de duplas de profissionais de nível técnico e de nível médio de ensino (oficineiros).

Sobre a necessidade de desenvolvimento de habilidades do campo da atenção psicossocial, é necessário afirmar que o trabalhador em saúde mental, além de ser um agente de cuidado, atua também como agenciador de uma rede de cuidados $^{19}$. O cumprimento dessas funções exige do profissional que atua no acolhimento a capacidade de identificar a multiplicidade de demandas explícitas e implícitas no discurso, além do conhecimento dos dispositivos da rede intersetorial de atenção integral: suas ofertas, suas funções e fluxos. É preciso, ainda, que o profissional tenha no horizonte a concepção de que seu trabalho deve atuar no sentido da ampliação dos direitos dos usuários e de sua autonomia e cidadania. 
Apesar dos avanços produzidos pelo paradigma da atenção psicossocial sobre a complexidade da compreensão do sofrimento mental, a concepção de clínica ainda tem forte referencial no paradigma biomédico, com ênfase na avaliação de sintomas, associação aos quadros psicopatológicos e intervenções medicamentosas.

Se, por um lado, o conhecimento psicopatológico não deve se restringir à decodificação dos sintomas a partir de uma nosologia que reduz a experiência do sofrimento a uma categoria, por outro, a apropriação de alguma teorização acerca da experiência do pathos é imprescindível. A ausência de uma perspectiva teórica a nortear o olhar e as ações do profissional no acolhimento inviabiliza uma leitura apropriada sobre o sofrimento apresentado, o que repercute nos processos decisórios subsequentes.

Outra situação observada foi o acolhimento de casos que chegam em situação de crise no serviço, "crise" por vezes traduzida como tal a partir exclusivamente da constatação de um quadro de agitação psicomotora por parte da criança ou adolescente.

Para os casos em "crise", a prioridade de intervenção é pela psiquiatria, pois se compreende a necessidade de urgência da intervenção medicamentosa, geralmente anterior a qualquer outra tentativa de cuidado. Na ausência de um médico no serviço, foram observados, por vezes, casos encaminhados diretamente para atendimento na emergência psiquiátrica, logo ali ao lado: "nós não atendemos emergência porque não temos sempre médico", disse uma profissional a uma família que chegava à recepção do CAPSi. É importante destacar o diferencial que a intervenção nas primeiras crises tem para o desenvolvimento posterior do quadro de sofrimento dos sujeitos nesta fase da vida, mostrando-se o acolhimento qualificado nessas situações uma chance valiosa para prevenção de novos episódios e do agravamento do $\mathrm{CasO}^{20}$. Chama atenção a necessidade de empoderamento e capacitação da equipe para sentir-se capaz de lidar com os casos em situação de crise para além das estratégias de silenciamento dos sintomas e de isolamento, repensando as práticas de cuidado no sentido de aproximação com a complexidade e a incerteza que cercam as crises neste campo, com a articulação de ações na equipe e na Rede de Atenção ${ }^{21}$.

Além dos desafios produzidos por essa especificidade da clínica da infância e adolescência, de nos remeter às nossas próprias experiências dessa fase e das relações vinculares que a constituem ${ }^{22}$, outras dificuldades são apontadas pelos profissionais, que atribuem ao acolhimento o potencial de produção de sofrimento para eles. O contato com as histórias de sofrimento, perpassadas por contextos de muita violência, diferentes vulnerabilidades e pobreza extrema, não raro gera angústia entre os profissionais que atuam no acolhimento, principalmente pela responsabilidade que lhes é atribuída para dar respostas às demandas, frente à fragilidade da rede de atenção, que possui poucas estratégias e serviços disponíveis. Uma técnica de enfermagem relatou em um de nossos contatos:

A gente não teve formação para estar aqui. No nosso curso, saúde mental era hospital psiquiátrico. A gente caiu aqui e de repente tem que dar respostas para problemas muito graves. É suicídio, é estupro, é muita pobreza. Não conto quantas vezes me tranquei numa sala dessas chorando porque sofro com as histórias que escuto aqui. E muitas vezes a gente não tem para onde encaminhar, mas a gente vai fazer o quê? (Diário de campo, outubro de 2015)

O sentimento de impotência é mencionado em diversos momentos de compartilhamento dos casos acolhidos com o restante da equipe técnica. Nesse sentido, é importante que o serviço crie, além de estratégias de educação permanente que sejam capazes de ampliar a capacidade resolutiva dos casos pelos profissionais, intervenções de cuidado à saúde mental dos trabalhadores. Dessa forma, acreditamos que, em primeira instância, sejam prioritárias as estratégias de ampliação da participação dos trabalhadores nos espaços decisórios e, como propõe Elia ${ }^{23}$, o trabalho com o coletivo de profissionais no sentido de formação de uma "equipe de CAPS", ancorada no desejo de atuação nesse espaço, com todas as nuances que esse serviço propõe em seu modelo de cuidado. 


\section{O encontro entre acolhedor e sujeitos em sofrimento}

Sobre o encontro entre o profissional responsável pelo acolhimento e os sujeitos em sofrimento que chegam pela primeira vez ao serviço com seus cuidadores (genitores, outros familiares ou representantes de instituições), debruçamo-nos sobre dois aspectos principais: as estratégias de vinculação com os sujeitos em sofrimento e a forma de apresentação do serviço.

Ao significarmos a produção de saúde enquanto movimento de responsabilização dos sujeitos e das comunidades sobre o cuidado de si e do outro, o direito à palavra torna-se princípio fundamental. "Ao falarem sobre si e ao se identificarem com suas próprias histórias, a criança e o adolescente veem possibilidades de encontrar novos significados e novas formas de inserção na sociedade e na família" 4 (p. 23). Essa premissa clínica e política envolve um alinhamento ético dos técnicos que trabalham em um CAPSi, pois reconhecemos que socialmente há ainda uma tendência a negar às crianças a fala e a expressão dos desejos, assim como, por vezes, são desconsiderados seus sofrimentos.

A priorização da fala das crianças e dos adolescentes no exercício de buscar uma linguagem que promova a comunicação (seja a linguagem verbal mais próxima do universo infantojuvenil, sejam outras formas de linguagem corporal, ou a utilização dos instrumentos lúdicos ou expressivos) foi observada como uma estratégia que permite melhor compreensão das queixas apresentadas, bem como a produção de autonomia e vinculação com os sujeitos. A disposição pessoal, observada entre os profissionais ao sentarem-se no chão para brincar junto com as crianças e ao criarem jogos com alguns recursos próprios para a expressão desse público, permite o distanciamento do discurso produzido pela família ou pelas instituições sobre o sujeito e a aproximação deste em sua expressão mais genuína.

Um segundo aspecto do acolhimento foi o discurso produzido sobre o serviço pelos profissionais ao apresentarem o funcionamento da instituição aos usuários e familiares. Observou-se que o discurso ora era atravessado pela intencionalidade de promover a vinculação (nos casos que se compreendia que deveriam ser acompanhados no CAPSi), com falas no sentido de exaltar elementos de identificação do serviço com o sujeito, ora era afetado pela pretensão de não fazê-la, perante os casos que seriam encaminhados a outros dispositivos.

Nesses últimos casos, conscientemente ou não, o discurso sobre o CAPSi tinha a potência de gerar o afastamento dos sujeitos em acolhimento do serviço. Identificamos narrativas como "não é justo colocar seu filho organizado aqui, com outros esquizofrênicos, com depressão grave", que denotam que, na expectativa de frustrar a identificação de uma demanda interpretada como "leve" com o tipo de necessidade a ser assistida no CAPSi, acaba-se por promover um discurso que distorce a caracterização do serviço e ainda tem a capacidade de gerar estigmas em torno dos usuários por ele acompanhados.

\section{Avaliação psicossocial do caso}

Outra dimensão do acolhimento é o seu intento de iniciar uma avaliação do caso. Para além da identificação de sintomas, típica do processo de avaliação em saúde mental em um modelo manicomial, a análise de um caso que chega a um CAPS deve contemplar a apreciação dos fatores de risco (variáveis que aumentam a vulnerabilidade para o desenvolvimento de uma psicopatologia ou para resultados negativos no desenvolvimento) e dos fatores de proteção (recursos pessoais ou sociais que diminuem ou inibem o impacto do risco) presentes na história e no contexto sociocultural atual do sujeito e de sua família.

Os fatores de risco para problemas de saúde mental entre crianças e adolescentes podem ser agrupados entre os biológicos (problemas vivenciados na gestação, no parto, ou complicações clínicas na primeira infância); genéticos (histórico de transtorno mental na família); psicossociais (disfunções na vida familiar e na inserção escolar; perda de vínculo com genitores; ausência de vinculação a grupos sociais, baixos níveis de suporte social); eventos de vida estressantes (altos níveis de estresse familiar, separação dos pais, perda de pessoa afetivamente significativa, evasão escolar); exposição a maustratos (violência intrafamiliar, violência em contexto escolar ou comunitário, abuso físico ou sexual); e fatores ambientais (baixa renda, más condições de moradia, acesso limitado à saúde e à educação)24,25. 
A identificação dos fatores de proteção é fundamental para a criação posterior de estratégias de cuidado, ao se configurarem enquanto potenciais para investimento terapêutico. Os fatores de proteção podem ser categorizados em atributos da criança (autonomia, autoestima, preferências), características da família (coesão, afetividade, clareza de regras e responsabilidades entre membros) e fontes de apoio individual ou institucional disponíveis para a criança e a família (apoio de outros familiares, suporte cultural, vinculação à instituições religiosas, etc. $)^{24}$.

A identificação dos fatores de risco e de proteção deve ser considerada em sua contextualização socio-histórica-cultural, em um esforço de não realizar a imposição de valores, referências e normas pessoais às famílias atendidas.

Observamos que, nas entrevistas iniciais realizadas no acolhimento dos casos que chegam pela primeira vez ao CAPSi, são priorizados aspectos do desenvolvimento da criança (gestação, parto, desenvolvimento na primeira infância), da dinâmica familiar (relação com familiares e identificação das pessoas com maior vínculo, relação com a autoridade dos pais e separação ou perda de pessoas significativas), da inserção social (dinâmica escolar, realização de outras atividades de esporte ou cultura, organização do lazer e relacionamento com outras crianças ou adolescentes) e da rotina (alimentação, sono e atividades que realiza cotidianamente).

$\mathrm{Na}$ escuta com familiares e instituições, é possível ampliar a leitura sobre o problema e, por vezes, desconstruir a demanda de cuidado especializado para a criança. Em alguns acolhimentos, por exemplo, foi possível identificar que o problema maior estava situado em uma crise no casamento dos genitores, ou na ansiedade da mãe em lidar com a vivência da maternidade, ou, ainda, nas dificuldades de manejo da família sobre as questões próprias da adolescência. Nesses casos, é importante que se acolha a demanda, que se construa junto com os sujeitos a ampliação da leitura do problema e que sejam dados os devidos encaminhamentos.

\section{Os encaminhamentos}

Ao discorrermos sobre os aspectos do acolhimento em um CAPSi, não podemos perder de vista o exercício de seus dois papéis fundamentais: o terapêutico e o gestor, que o incumbe de desenvolver ações para conhecimento e ordenação das diferentes demandas que concernem à saúde mental da infância e adolescência no território sob sua responsabilidade ${ }^{3}$.

Desse modo, recai sobre o CAPSi a responsabilidade de direcionamento para o cuidado adequado das crianças e adolescentes que chegam ao serviço, ainda que se reconheça que não é o CAPSi o lugar que responderá a essas demandas. É importante compreender que "o encaminhamento é necessariamente um procedimento clínico, em que o paciente e o profissional estão implicados na decisão institucional"16 (p. 25). Esse destaque é fundamental, sobretudo, para desconstruir a compreensão difundida entre muitos serviços públicos do encaminhamento como um mero trâmite burocrático.

O encaminhamento deve ser realizado no caso de identificação de outro dispositivo que possa responder melhor às necessidades do usuário e deve ser realizado de forma implicada e corresponsável, com o acompanhamento pelo profissional que acolheu o caso no CAPSi até o atendimento e inclusão do usuário no outro serviço. Esse processo pode envolver comunicação interinstitucional, visitas para estabelecimento de parcerias, discussão de caso entre as equipes envolvidas, ou ainda o atendimento conjunto pelos diferentes dispositivos.

É importante que a equipe reflita sobre estratégias que podem tornar mais efetivos os encaminhamentos realizados, impactando na redução dos longos itinerários realizados pelas famílias em busca de cuidado. O contato direto com outras instituições, com a discussão do caso acolhido e a garantia de disponibilidade do outro dispositivo de dar continuidade ao cuidado, tem chances maiores de gerar um encaminhamento efetivo do que a entrega de uma lista de contatos de instituições para as famílias fazerem a busca por conta própria.

Um nó na rede identificado pelos profissionais do CAPSi é a resolutividade nos encaminhamentos com a continuidade da atenção nos outros pontos de atenção da rede. Com poucos serviços disponíveis e com longas filas de espera nos existentes, o encaminhamento dos casos sob a incerteza 
de serem assumidos por outros pontos da atenção confronta-se com a impossibilidade de abarcar o cuidado desses no CAPSi. Porém, percebe-se no cotidiano do serviço que muitos casos, reconhecidos como de responsabilidade de outros serviços, acabam sendo acompanhados no CAPSi por não haver para onde encaminhá-los ou por não se confiar na capacidade de outro serviço ofertar o devido cuidado.

Destaca-se aqui a necessidade de investimento contínuo do serviço no conhecimento dos diferentes dispositivos de cuidado a essa população, incluindo aqui aqueles de oferta nos campos da arte, esporte, lazer, cultura e iniciação profissional.

\section{Considerações finais}

A etnografia do acolhimento no CAPSi permitiu a compreensão de como, para além da normatização que rege as práticas dos serviços segundo os princípios do SUS, configuram-se as tensões, ambiguidades e conflitos na conformação do cuidado neste serviço, regido por diferentes compreensões e valores em torno do sofrimento psíquico. A escolha do acolhimento enquanto espaço privilegiado para essa análise justificou-se pelo reconhecimento de que a forma de organização e vivência do encontro de usuários e profissionais neste momento é importante demarcador para continuidade do cuidado, seja nesse serviço ou em outras instituições.

Foi possível nesta análise identificar dois aspectos centrais do acolhimento: a vinculação e a responsabilização. Observa-se que os modos de operar as relações (entre profissionais e usuários e entre os profissionais), e de apresentação da instituição (na concretude espacial e na produção do discurso sobre o papel e as possibilidades de intervenção do serviço), a forma de organização institucional (turnos e profissionais disponíveis para acolhimento, tempo e filas de espera) e como são dados os encaminhamentos dos casos acolhidos definem a possibilidade de vinculação do usuário ao serviço e/ou ao profissional. Essa vinculação pode ser traduzida na percepção do usuário de ser respeitado e acolhido em seu sofrimento e no seu reconhecimento da capacidade do serviço e/ou do profissional de oferecer respostas ao seu problema, ainda que estas sejam o encaminhamento para outro dispositivo ou estratégia de cuidado.

Quanto à responsabilização, temos, em primeira instância, a necessidade de, desde o acolhimento, intervir na produção em saúde como movimento de responsabilização dos sujeitos sobre o cuidado de si e do outro, premissa inaugurada com o paradigma psicossocial ao deslocar o sujeito do lugar daquele que apenas sofre as consequências de seus conflitos. Esse movimento implica na necessidade de conferir a fala aos sujeitos em sofrimento: no campo da infância e adolescência, é necessário considerar ainda a mudança histórica, cultural e política da retirada da criança e do adolescente do lugar de objetos de disciplinarização e normatização para seu reconhecimento enquanto sujeitos de direitos. Em outra dimensão, o acolhimento apresenta-se como importante espaço de gerenciamento das demandas emergentes do território, o que implica no exercício de gestão da rede de atenção local para ampliação das possibilidades de resposta aos problemas apresentados pelos sujeitos que chegam ao serviço.

A responsabilização do CAPSi não pode ser, assim, somente junto com os casos que potencialmente podem ser acompanhados nesta unidade, mas também daqueles que podem beneficiar-se de uma intervenção breve - como uma escuta qualificada, uma avaliação mais processual - ou de um

direcionamento implicado para continuidade do acompanhamento em outro ponto da rede. Essa premissa aponta para a necessidade de o CAPSi atuar em seu território junto com os serviços de educação, assistência social, saúde e demais setores envolvidos no cuidado ao público infantojuvenil, no sentido de problematizar o processo de medicalização embutido nos encaminhamentos aos CAPSi, com o questionamento dos elementos contextuais (socioeconômicos, culturais, políticos, institucionais) dos enquadrados "criança-problema" ou "adolescente-problema", que expressam problemas de ordem coletiva. Esse movimento envolve a desconstrução da demanda de acompanhamentos especializados e a criação de estratégias de abarcamento da expressão e vivência desses sujeitos, que rompem com o ideal de criança e adolescente "ajustado", "adequado" às normas institucionais. 
Desta pesquisa, emerge a necessidade de discussão sobre o trabalho em saúde mental, no qual predomina a reprodução na formação acadêmica do modelo manicomial de intervenção em saúde mental, com centralidade nos procedimentos biomédicos e na relação hierárquica de poder entre profissional e usuário. Evidencia-se a demanda de um investimento maciço em espaços de educação permanente que intervenham na cultura profissional e institucional, expressa, por vezes, em discursos e práticas manicomiais dentro dos serviços substitutivos.

Diante dessas considerações, assumimos o acolhimento enquanto um ato clínico, que exige conhecimentos técnicos e habilidades para sua operacionalização, mas também como um compromisso ético e político com as populações, enquanto estratégia de afirmação das crianças e adolescentes como sujeitos de direitos e como espaço de intervenção que deve direcionar-se à garantia do cuidado e proteção integral a este público.

\section{Colaboradores}

A autora Carolina Pinheiro Moreira participou, como autora principal, da concepção da pesquisa, produção, análise e interpretação dos dados e da redação do manuscrito, incluindo a discussão dos dados, revisão e aprovação da versão final do artigo. As coautoras Mônica de Oliveira Nunes Torrente e Vládia Jamile dos Santos Jucá contribuíram substancialmente em todas as etapas da elaboração do artigo, incluindo a discussão dos dados, revisão e aprovação da versão final do artigo.

\section{Referências}

1. Ministério da Saúde (BR). Portaria $n^{\circ} 336$, de 19 de fevereiro de 2002. Define e estabelece diretrizes para o funcionamento dos Centros de Atenção Psicossocial. Diário Oficial da União. 19 Fev 2002. Sec 1, p. 22.

2. Ministério da Saúde (BR). Caminhos para uma Política de Saúde Mental Infantojuvenil. Brasília: Ministério da Saúde; 2005. (Série B. Textos Básicos em Saúde).

3. Couto MCV, Duarte CS, Delgado PGG. A saúde mental infantil na Saúde Pública brasileira: situação atual e desafios. Rev Bras Psiquiatr. 2008; 30(4):390-8.

4. Ministério da Saúde (BR). Atenção psicossocial a crianças e adolescentes no SUS: tecendo redes para garantir direitos. Brasília: Ministério da Saúde; 2014.

5. Schimidt MB, Figueiredo AC. Acesso, acolhimento e acompanhamento: três desafios para o cotidiano da clínica em saúde mental. Rev Latinoam Psicopatol Fund. 2009; 12(1):130-40.

6. Jorge MSB, Pinto DM, Quinderé PHD, Pinto AGA, Sousa FSP, Cavalcante CM. Promoção da saúde mental - tecnologias do cuidado: vínculo, acolhimento, co-responsabilização e autonomia. Cienc Saude Colet. 2011; 16(7):3051-60. 
7. Ministério da Saúde (BR). Acolhimento nas práticas de produção de saúde. Brasília: Ministério da Saúde; 2006.

8. Silva Junior AG, Mascarenhas MTM. Avaliação da atenção básica em saúde sob a ótica da integralidade: aspectos conceituais e metodológicos. In: Pinheiro R, Mattos R, organizadores. Cuidado: as fronteiras da integralidade. Rio de Janeiro: IMSUERJ; 2004. p. 241-57.

9. Véras RM, organizadora. Introdução à etnografia institucional: mapeando práticas na assistência à saúde. Salvador: EDUFBA; 2014.

10. Nunes $M O$, Jucá VJ, Pitta $A M F$, Torrenté $M$. A articulação da experiência dos usuários nas microculturas dos centros de atenção psicossocial: uma proposta metodológica. Estud Pesqui Psicol. 2010; 10(1):204-20.

11. Ministério da Saúde (BR). Manual de estrutura física dos centros de atenção psicossocial e unidades de acolhimento: orientações para elaboração de projetos de construção de CAPS e de UA como lugares da atenção psicossocial nos territórios. Brasília: Ministério da Saúde; 2013.

12. Ministério da Saúde (BR). Política Nacional de Humanização. Brasília: Ministério da Saúde; 2010.

13. Secretaria de Estado da Saúde (MG). Atenção em Saúde Mental (Linha-Guia). Belo Horizonte: SES; 2006.

14. Amarante P. Saúde mental e atenção psicossocial. Rio de Janeiro: Fiocruz; 2007.

15. Peixoto MM, Mourão ACN, Serpa Junior OD. O encontro com a perspectiva do outro: empatia na relação entre psiquiatras e pessoas com diagnóstico de esquizofrenia. Cienc Saude Colet. 2016; 21(3):881-90.

16. Pinto RF. CAPSi para crianças e adolescentes autistas e psicóticas: a contribuição da psicanálise na construção de um dispositivo clínico [dissertação]. Rio de Janeiro (RJ): Universidade do Estado do Rio de Janeiro; 2005.

17. Carvalho LB. Tessituras éticopolíticas do cuidado na saúde mental [tese]. Fortaleza (CE): Universidade Federal do Ceará; 2014.

18. Maynart WHC, Albuquerque MCS, Brêda MZ, Jorge JS. A escuta qualificada e o acolhimento na atenção psicossocial. Acta Paul Enferm. 2014; 27(4):300-4.

19. Ramminger T, Brito JC. "Cada CAPS é um CAPS": uma coanálise dos recursos, meios e normas presentes nas atividades dos trabalhadores de saúde mental. Psicol Soc. 2011; 23 N Spe:150-60.

20. Costa II. Adolescência e a primeira crise psicótica: problematizando a continuidade entre o sofrimento psíquico normal e o psíquico grave. In: Anais do II Congresso Internacional de Psicopatologia Fundamental; 2006; Belém. Belém: Universidade Federal do Pará; 2006. Disponível em: http://www.psicopatologiafundamental.org/uploads/ files/ii_congresso_internacional/mesas_redondas/ii_con._adolescencia_e_primeira_crise_ psicotica.pdf

21. Zeferino MT, Rodrigues J, Assis JT, organizadores. Crise e urgência em saúde mental: fundamentos da atenção à crise e urgência em saúde mental. Florianópolis: Universidade Federal de Santa Catarina; 2014.

22. Jucá V. A residência no CAPSi: especificidades do cuidado na saúde mental infantojuvenil. In: Nunes $M$, Torrenté $M$, Prates $A$, organizadores. O otimismo das práticas: inovações pedagógicas e inventividade tecnológica em uma residência multiprofissional em saúde mental. Salvador: EDUFBA; 2015. p. 263-86.

23. Elia L. Uma equipe muito peculiar: a equipe do CAPS. In: Kamers $M$, organizadora. Por uma (nova) psicopatologia da infância e da adolescência. Belo Horizonte: Escuta; 2015. p. 243-66. 
24. Ramiresi VRR, Passarini DS, Flores GG, Santos LG. Fatores de risco e problemas de saúde mental de crianças. Arq Bras Psicol. 2009; 61(2):1-14.

25. Matsukura TS, Fernandes ADSA, Cid MFB. Fatores de risco e proteção à saúde mental infantil: o contexto familiar. Rev Ter Ocup Univ. 2012; 23(2):122-9.

Moreira CP, Torrenté MON, Jucá VJS. Análisis del proceso de acogida en un Centro de Atención Psico-social Infanto-juvenil: consideraciones de una investigación etnográfica. Interface (Botucatu). 2018; 22(67):1123-34.

Este artículo analiza las prácticas de acogida a niños y adolescentes desarrolladas por los profesionales de un Centro de Atención Psico-social Infanto-juvenil (CAPSi) del municipio de Salvador, Bahia, Brasil. En una investigación etnográfica se analizaron los aspectos institucionales y clínicos envueltos, desde la llegada del usuario por la primera vez al servicio hasta el direccionamiento dado a su caso. En el análisis se utilizaron categorías que se refieren a la organización del ambiente, a los procesos de trabajo interdisciplinarios, a las estrategias de evaluación psico-social y a la continuidad del cuidado. Se muestra como la organización y vivencia del encuentro de usuarios y profesionales en el momento de la acogida son importantes demarcadores para la forma de vinculación y toma de responsabilidad con los casos que llegan al servicio, señalando también necesidades específicas para inversión en la formación de los trabajadores de salud mental y en la reorganización de los procesos de trabajo en el CAPSi.

Palabras clave: Salud mental infanto-juvenil. Acogida. Procesos de trabajo.

Submetido em 03/09/17. Aprovado em 04/12/17. 